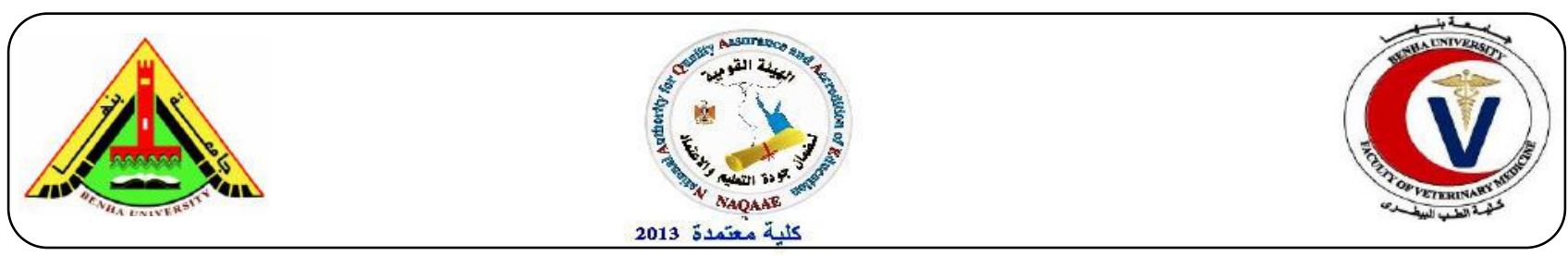

\title{
Identification of Pyogenic Bacteria in Human and Animals Conventionally and Non-nucleic Acid Molecularly Using MALDI-TOF MS
}

\author{
Ahlam A. Gharib ${ }^{a}$, Nourhan K. Abd El-Aziz ${ }^{a}$, Ashraf Hussein ${ }^{b}$ and Eman A. A. Mohammed ${ }^{a}$ \\ ${ }^{a}$ Microbiology Department, Faculty of Veterinary Medicine, Zagazig University, Egypt \\ ${ }^{b}$ Avian and Rabbit Medicine Department, Faculty of Veterinary Medicine,Zagazig University, Egypt
}

\section{A B S T R A C T}

Sepsis is considered a race to death between pathogens and host immune system, associated with a high mortality worldwide. Until now, blood cultures (BCs) are still the "gold standard" for identification of pathogens causing sepsis. Its major drawback is long turn around time (TAT) of 24-48 $\mathrm{h}$ up to several days, which is not compatible with the need for early sepsis diagnosis. Molecular assays as matrix-assisted laser- desorption ionization time-of-flight mass spectrometry(MALDI-TOF MS) reduce the TAT. Herein, the main aim of the study is to develop rapid and highly sensitive molecular proteomic non-nucleic acid assay for identification (ID) of the most common bacteria causing sepsis and pyogenic infections in human and animals. Eighty clinical samples, including 50 animal pus samples and 30 neonatal whole blood samples were subjected for conventional and molecular identification using VITEK-MS. About $70 \%$ of samples were BC positive, including $33 / 50(66 \%)$ of animal pus samples and 23/30 (76.7\%) of neonatal blood samples. The identified bacterial species were only three conventionally versus twelve using VITEK-MS, with variable confidence value (C.V) that was $99.9 \%$ for 55/58 (94.8\%) isolates, $50 \%$ for 2/58 (3.4\%) isolates and $26.5 \%$ with $1 / 58(1.74 \%)$ isolate. The species-level identification for Streptococci was more challenging than for Staphylococci and Enterococci with only $50 \%$ C.V for S. dysagalactiae subsp. dysagalactiae. Culture provided concordant species- and genus-level identification with VITEKMS for 24/58(41.3\%) and 34/58(58.6\%) of isolates, respectively. The overall concordance was $100 \%$ for all isolates except $P$. aeruginosa was $87.5 \%$.

Keywords: VITEK-MS, sepsis, pyogenic bacteria

(http://www.bvmj.bu.edu.eg)

(BVMJ-35(1): 263-273, 2018)

\section{INTRODUCTION}

Pyogenic bacteria is the usual cause of suppuration, including $S$. aureus, S. pyogenes, P. aeruginosa, Proteus spp, E. coli, Klebsiella spp, C. perfringes and Bacteroides. They occur in abscesses, burn or wound infections, cellulitis, bites, suppurative lymphadenitis and pyomyositis. An abscess is a localized collection of pus into a cavity formed by tissue liquefaction(Siqueira \& Rocas 2013), living, dead and disintegrated neutrophils, 
living and dead bacteria, cells debris and inflammatory exudates (Verma 2012).

Sepsis is a severe inflammatory response to infection, that rapidly developed and produced high mortality of 200,000 deaths per year(Chun et al. 2015). Bacteraemia is bacterial circulation in blood, whereas sepsis is bacteraemia with clinical signs as fever, hypotension, tachycardia and tachypnea (Dreyer 2012). Sepsis is caused by microbial invasion from local infection into bloodstream, (Reinhart et al. 2012), evolving as $\geq 2$ systemic inflammatory response syndrome (SIRS) criteria (Kaukonen et al. 2015) to severe sepsis, septic shock (Gaieski et al. 2013),multiple organ dysfunction syndrome (MODS) andmultiple organ failure (MOF), in order of increasing severity. Sepsis is caused by Gram-positive (GP) and Gramnegative (GN) bacteria, anaerobes, fungi, viruses or parasites (Dellinger et al. 2013 and Iskander et al. 2013). Bacterial sepsis is a dangerous disease with high mortality rates.S. aureus and Streptococcus spp are the most frequent GP bacteria causing sepsis (Morel et al. 2015), whereas E. coli (Schaub et al. 2014), K. pneumoniae and $P$. aeruginosa are the predominant GN bacteria (Ranieri et al. 2012). Sepsis is mono-microbial infection, with minor polymicrobial infections (10-20 $\%)$ (Ngo et al. 2013), while pyogenic infections are polymicrobial or monomicrobial, endogenous or exogenous (Verma 2012).

The BCs remain the gold standards for BSI diagnosis(Dellinger et al. 2013). Phenotypic characterization from positive $\mathrm{BCs}$ include sub-culture, microscopy and biochemical tests (Laakso 2013).Classic BCs are timeconsuming(Chang et al. 2015) and require 48-72 h for bacterial growth, up to 5 days (Loonen et al. 2014) for fastidious bacteria(Mulvey et al. 2012), 4-24 h for identification and an additional $24 \mathrm{~h}$ for antimicrobial susceptibility test (Cambau \&
Bauer 2015) with results are usually false negative (Liesenfeld et al. 2014). Owing to long TAT, a safety strategy utilizes empirical antibiotics in the first hour of sepsis onset (Dellinger et al. 2013). However, this initial treatment is inadequate for $47 \%$ of patients (Jernberg et al. 2010).A delay or failure in identification extends the antibiotic courses causing deleterious adverse effects as development of antibiotic resistant bacteria, collateral damage to normal gut flora, opportunistic pathogen colonization as $C$. difficile and/or Enterobacteriaceae selection with transferable drug resistance (Farrell et al. 2013).The early detection within the first 6$12 \mathrm{~h}$ is essential for favorable outcome in sepsis (Wang et al., 2014). Rapid molecular assays are needed especially in emergency units and acute critical- care settings (Stoneking et al. 2013).They are performed on positive $\mathrm{BC}(\mathrm{s})$ or directly on blood (Jordana-Lluch et al. 2013), either amplified nucleic acid- based techniques (NATs),nonamplified NATs or non-NATs(Kothari et al. 2014)such as MALDI-TOF MS which has become an attractive option to rapidly identify many pathogens. It is used in this study as a recent rapid proteomic method identifying bacteria by their conserved ribosomal proteins(Chun et al. 2015). Therefore, the main aim of the study is to develop rapid and highly sensitive molecular proteomic nonnucleic acid assay for identification (ID) of the most common bacteria causing sepsis and pyogenic infections in human and animals.

\section{MATERIALS AND METHODS}

A total of 80 clinical samples were used in this study, including 50 pus samples (code no 1a: 50a) from animal abscesses and 30 neonatal whole blood samples (code no $1 \mathrm{~h}$ : 30h) with suspected sepsis admitted to neonatal intensive care unit (NICUs) at ElAhrar General Hospital, Zagazig, Sharkia, Egypt. All neonates received at least 5 days of antibiotics. The most frequent clinical signs 
were respiratory distress and mild perinatal asphyxia, while the most frequent laboratory abnormalities were neutrophilia, leukopenia and thrombocytopenia. Clinical data of cases and patients are not shown.

Bacterial isolation and identification

Pus and whole blood samples were inoculated on blood agar and incubated aerobically or with $5 \% \mathrm{CO}_{2}$ at $37^{\circ} \mathrm{C}$ for $24 \mathrm{~h}$ up to 5 days(Faria et al. 2015). Blind subcultures were made on solid media, including MacConkey's and eosin methylene blue (EMB) for isolation of Gram-negative (GN) bacteria; mannitol salt agar (MSA)and Edward's agar for isolation of Gram-positive (GP) bacteria with $5 \% \mathrm{CO}_{2}$ incubation for isolation of streptococci, as well as Brain Heart Infusion (BHI) broth at $\mathrm{pH} 9.6$ and incubated at $10-45^{\circ} \mathrm{C}$ for isolation of enterococci.

Conventional identification of bacterial isolates

Suspected clinical isolates were identified using Gram's stain and biochemical tests (Boutin et al. 2015), including catalase and coagulase for staphylococcal isolates; salt and bile tolerance and esculin hydrolysis tests for enterococcal isolates; oxidase, IMVC, urease and TSI tests for GN isolates. Bacterial isolates were preserved frozen in BHI broth with $30 \%$ glycerol at $-20{ }^{\circ} \mathrm{C}$ (Quiles et al. 2015).

Molecular identification of bacterial isolates by MALDI-TOF MS

A pure colony of fresh overnight subculture on blood agar was spotted directly onto a well of target slide using a $1.0 \mu$ loop, covered with $1 \mu \mathrm{l}$ matrix solution and air dried for $5 \mathrm{~min}$ at room temperature to cocrystallize with sample, before insertionintoVITEK-MS instrument for target interrogation and generation of spectra (Luo et al. 2015). In case of polymicrobial $\mathrm{BC}(\mathrm{s})$,colonies had variant morphologies were selected and analyzed separately (Barnini et al. 2015). a. Generation of mass spectra

Spectra were recorded in positive linear mode within a mass range from 2000 to $20,000 \mathrm{Da}$ (laser frequency of $20 \mathrm{~Hz}$, acceleration voltage $20 \mathrm{kV}$, IS2 voltage maintained at $18.6 \mathrm{kV}$, extraction delay time $200 \mathrm{~ns}$ ). For each spectrum, 500 laser shots (50 laser shots from different positions of the target spot, 10 times) were collected by MS. The generated mass fingerprints were processed by computer software and the advanced spectrum classifier algorithm which was associated with VITEK-MS and identified an organism by comparing the obtained spectrum (presence and absence of specific peaks) with those of the typical spectrum of each species in a reference spectra database (Verroken et al. 2015).

\section{b. Interpretation of MALDI-TOF MS results}

Confidence value (C.V)

It represented similarity of specific peaks between generated and database spectra. Samples had single identification with any C.V highly confident at species level, whereas only genus-level identification result was obtained when C.V of a 'low discrimination' (LD), including species of the same genus. A 'No ID' result was denoted if (i) no identification provided or (ii) identification including species of different genera. Samples with 'No ID' were retested and repeated result was considered as final. A C.V of $99.9 \%$ meant a perfect match and that of $60-99.8 \%$ indicated spectra, close to that of a reference spectrum (Luo et al. 2015).

The VITEK-MS and conventional results were compared and correlated as follows; total concordance, when MALDI-TOF MS and phenotypic identification agreed at species level, MS was considered correct species identification; partial concordance, both methods matched at genus level; no reliable result, when VITEK- MS provided 
No ID; no peaks, when no protein spectrum was obtained; and discordant results, when identification by both methods did not match.

\section{RESULTS}

After BC incubation at $37^{\circ} \mathrm{C}$ for $24-48 \mathrm{~h}$ aerobically with/without $5 \% \mathrm{CO}_{2}, 56 / 80$ (70 $\%)$ samples were $\mathrm{BC}$ positive, including $33 / 50(66 \%)$ animal pus samples and 23/30 (76.7\%) neonatal blood samples. Bacterial isolates were identified by standard conventional phenotypic methods (Fig. 1), whichrevealed that among pus samples, 31 were monomicrobial and only 2 samples (code no $4 \mathrm{a}$ and 23a) were polymicrobial at Gram stain.Whereas, all blood samples appeared monomicrobial at Gram stain.
Distribution of bacterial isolates from pus and blood culture

All 58 bacterial isolates of animal and human origin were identified as 30 (51.7\%) GP, including Staphylococcus ( $\mathrm{n}=$ 23), Streptococcus $(n=5)$, Bacillus $(n=1)$ and non-Bacillus spp $(\mathrm{n}=1)$ and $28(48.3 \%)$ GN isolates, including Enterobacteriaceae $(\mathrm{n}=19)$ and non-Enterobacteriaceae $(\mathrm{n}=9)$ (Table 1).

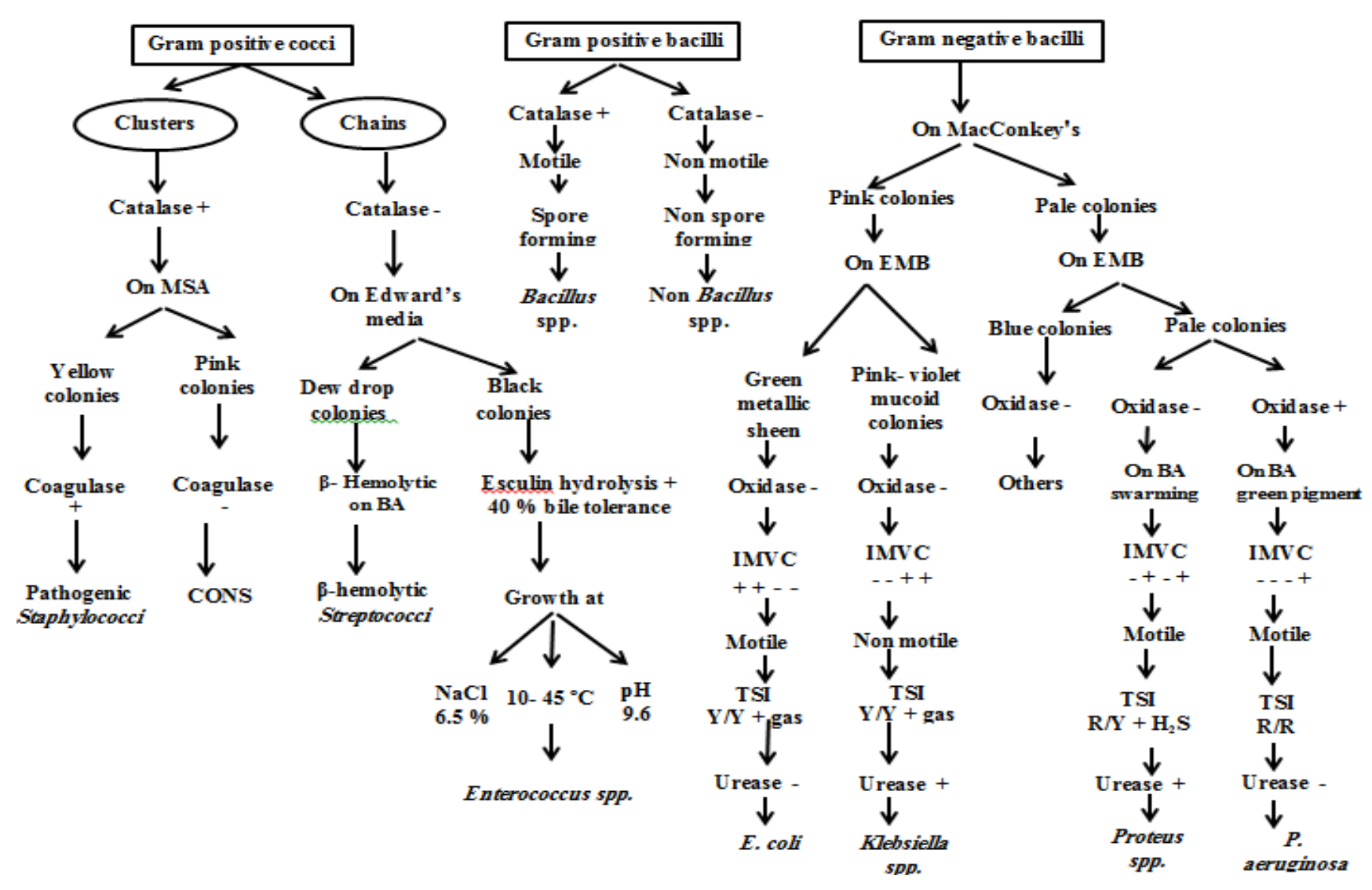

Fig.1. Flowchart of culture and phenotypic identification of bacterial isolates recovered from animal pus and neonatal blood with suspected sepsis. BA, blood agar; Y, yellow; R, red; MSA, mannitol salt agar; EMB, eosin methylene blue agar; TSI, triple sugar iron agar test; IMVC, indole, methyl red, Vogusproskour and citrate utilization tests; CONS, coagulase negative Staphylococci.

Table 1. Distribution of bacterial isolates from pus and blood samples 


\begin{tabular}{|c|c|c|c|c|c|c|}
\hline \multirow{3}{*}{$\begin{array}{l}\text { Bacterial species } \\
\text { Gram positive cocci }\end{array}$} & \multicolumn{2}{|c|}{ Animal pus $(n=35)$} & \multicolumn{3}{|c|}{ Neonatal blood $(n=23)$} & \\
\hline & \multirow[t]{2}{*}{ No. } & \multirow[t]{2}{*}{$(\%)$} & \multicolumn{2}{|c|}{$\begin{array}{l}\text { No. } \\
(\%)\end{array}$} & \multicolumn{2}{|c|}{ Correct ID at } \\
\hline & & & & & \multirow{2}{*}{$\begin{array}{l}\text { Species } \\
\text { level }\end{array}$} & \multirow[t]{2}{*}{ Genus level } \\
\hline Staphylococcus aureus & 6 & (17.14) & 4 & $(17.39)$ & & \\
\hline & & & & & 10 & 0 \\
\hline CONS & 7 & $(20)$ & 6 & $(26.08)$ & 0 & 13 \\
\hline Enterococcus spp. & 2 & $(5.71)$ & 1 & $(4.34)$ & 0 & 3 \\
\hline$\beta$ hemolytic Streptococci & 2 & $(5.71)$ & 0 & 0 & 0 & 2 \\
\hline Gram positive bacilli & & & & & & \\
\hline Bacillus spp. & 1 & $(2.85)$ & 0 & 0 & 0 & 2 \\
\hline NonBacillus spp. & 1 & $(2.85)$ & & & & \\
\hline Total GPbacteria & 19 & $(54.28)$ & 11 & $(47.82)$ & 10 & 20 \\
\hline \multicolumn{7}{|l|}{ Gram negative bacilli } \\
\hline Escherichia coli & 4 & $(11.42)$ & 2 & $(8.69)$ & 6 & 0 \\
\hline Klebsiella spp. & 1 & $(2.85)$ & 7 & $(30.43)$ & 0 & 8 \\
\hline Proteus spp. & 5 & $(14.28)$ & 1 & $(4.34)$ & 0 & 5 \\
\hline Pseudomonas aeruginosa & 6 & (17.14) & 2 & $(8.69)$ & 9 & 0 \\
\hline Total GN bacteria & 16 & $(45.71)$ & 12 & $(52.17)$ & 15 & 13 \\
\hline Total isolates $(n=58)$ & 35 & & 23 & & 25 & 33 \\
\hline
\end{tabular}

No., number; GP, Gram positive; GN, Gram negative; ID, identification

Proteomic molecular identification of bacterial isolates by MALDI-TOF-VITEKMS

The 58 bacterial isolates of animal and human origin were identified by VITEK-MS assay and 12 bacterial species were detected, comprising the most common pathogens causing pyogenic infection and sepsis in animals and neonates.Correct species level identification was consistently obtained for all isolates with a variable C.V, including $S$. aureus $(\mathrm{n}=10), S$. epidermidis $(\mathrm{n}=12)$, Staphylococcusxylosus $(\mathrm{n}=1)$, E. faecalis $(\mathrm{n}=$ 3), S. dysagalactiae subspp. dyasgalactiae $(\mathrm{n}=2)$, Bacillus licheniformis $(\mathrm{n}=1)$ and Lactobacillus rhamnosus $(\mathrm{n}=1)$ among $30 \mathrm{GP}$ isolates; in addition to $E$. coli $(\mathrm{n}=6), K$. pneumonia $(\mathrm{n}=8), P$. mirabilis $(\mathrm{n}=6), P$. aeruginosa $(\mathrm{n}=7)$ and Delftiaacidovorans $(\mathrm{n}=$
1) among $28 \mathrm{GN}$ isolates. Overall, VITEKMS correctly identified to a species level 55/58 (94.8 \%) isolates with $99.9 \%$ C.V; $2 / 58(3.4 \%)$ isolates with $50 \% \mathrm{C} . \mathrm{V}$ and $1 / 58$ $(1.7 \%)$ isolate with $26.5 \%$ C.V identified as L. rhamnosus in one animal isolate (Table 2). Distribution of bacterial species among pus and blood isolates using VITEK-MS

In the 35 animal isolates, GP were more common than GN bacteria with a frequency of 19/35 (54.2\%) and 16/35 (45.7\%) respectively. The two polymicrobial pus samples were confirmed by VITEK-MS as $B$. licheniformis andE. faecalis as well asE. coli and $P$. mirabilis with a C.V of $99.9 \%$.The 23 human isolates included 11/23 (47.82\%) Gp and 12/23 (52.17\%) GN bacteria (Table 2).

Table 2. Distribution of bacterial isolates identified by VITEK-MS from pus and blood samples 


\begin{tabular}{|c|c|c|c|c|c|c|}
\hline \multirow[t]{2}{*}{ Bacterial species } & \multicolumn{2}{|c|}{ Animal pus $(n=35)$} & \multicolumn{2}{|c|}{ Neonatal blood $(n=23)$} & \multirow{2}{*}{$\begin{array}{l}\text { Tota } \\
1\end{array}$} & \multirow[t]{2}{*}{ C.V \% } \\
\hline & & $(\%)$ & No. & $(\%)$ & & \\
\hline \multicolumn{7}{|l|}{ Gram positive cocci } \\
\hline Staphylococcus aureus & 6 & $(17.14)$ & 4 & $(17.3)$ & 10 & 99.9 \\
\hline Staphylococcus epidermidis & 6 & $(17.14)$ & 6 & $(26)$ & 12 & 99.9 \\
\hline Staphylococcus xylosus & 1 & $(2.85)$ & 0 & - & 1 & 99.9 \\
\hline Enterococcus faecalis & 2 & $(5.71)$ & 1 & $(4.34)$ & 3 & 99.9 \\
\hline $\begin{array}{l}\text { S. dysagalactiae subspp } \\
\text { dysagalactiae }\end{array}$ & 2 & $(5.71)$ & 0 & 0 & 2 & 50 \\
\hline Gram positive bacilli & & & & & & 99.9 \\
\hline Bacillus licheniformis & 1 & $(2.85)$ & 00 & & 1 & 26.5 \\
\hline Lactobacillus rhamnosus & 1 & $(2.85)$ & 00 & & 1 & \\
\hline Total GP bacteria & 19 & $(54.28)$ & 11 & $(47.82)$ & 30 & \\
\hline \multicolumn{7}{|l|}{ Gram negative bacilli } \\
\hline Escherichia coli & 4 & $(11.42)$ & 2 & $(8.69)$ & 6 & 99.9 \\
\hline Klebsiellapneumonia & 1 & $(2.85)$ & 7 & $(30.43)$ & 8 & 99.9 \\
\hline Proteus mirabilis & 5 & $(14.28)$ & 1 & $(4.34)$ & 6 & 99.9 \\
\hline Pseudomonas aeruginosa & 5 & $(14.28)$ & 2 & $(8.69)$ & 7 & 99.9 \\
\hline Delftiaacidovorans & 1 & $(2.85)$ & 0 & 0 & 1 & 99.9 \\
\hline Total GNbacteria & 16 & $(45.7)$ & $12(5$ & 17) & 28 & \\
\hline Total & 35 & & 23 & & 58 & \\
\hline
\end{tabular}

Culture versus VITEK-MS

The results obtained by VITEK-MS and routine culture methods were compared (Table 3).Twelvebacterial species were identified using VITEK-MS versus three only by conventional methods.P. aeruginosawas detected in 8 isolates by culture and 7 isolates by VITEK-MS. This misidentification was due Delftiaacidovorans were oxidase positive, pale colonies on MacConkey's and EMB agar. 
Table 3. Discrepancy between culture and VITEK-MS results

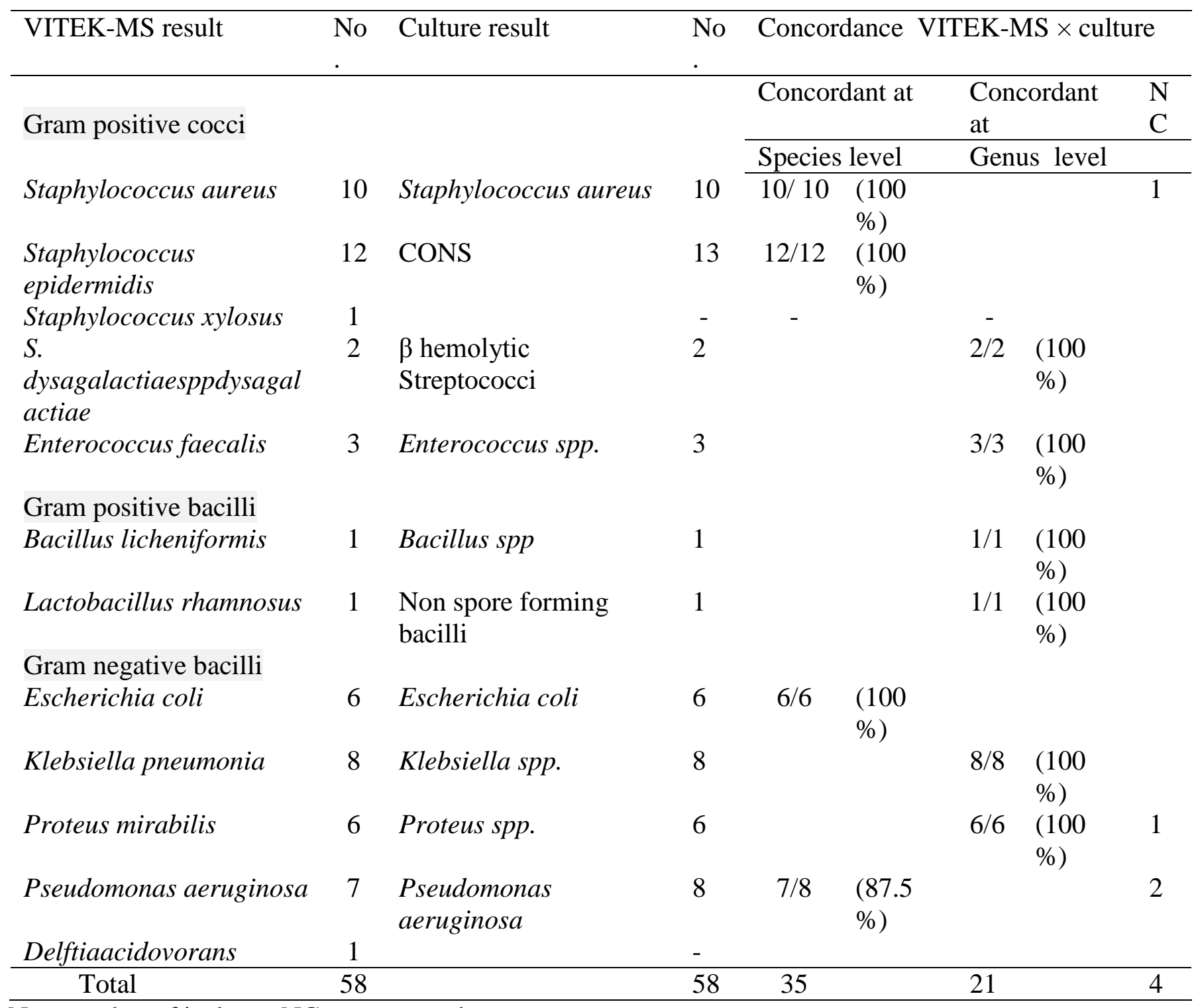

No., number of isolates; NC, not concordant

\section{DISCUSSION}

The gold standard for diagnosing sepsis is BC. The obtained result revealed a positive $\mathrm{BC}(\mathrm{s})$ in $66 \%$ of animal pyogenic infections and $76.7 \%$ of neonatal sepsis. It was higher than those reported by Lukacs \& Schrag (2012), Afshari et al. (2012),Loonen et al. (2014)and Roland \& Frank (2014)who estimated a positive $\mathrm{BC}(\mathrm{s})$ in neonatal sepsis as

$40 \%$,

$60 \%, 40 \%$ and $20 \%$, respectively. Failure in bacterial isolation and negative culture may be due to incorrect sampling, inadequate specimen conservation, low microbial concentration in sample, non-culturable bacteria (Rampini et al., 2011), small sample volume, VBNC (Jiang et al., 2013), fastidious, slow growing bacteria, antibiotic pre-treatment (Loonen et al. 2014), intracellular pathogens (Cambau \& Bauer 2015), toxin producing pathogens as $S$. pyogenesor $S$. aureus (Liang et al., 2013).

Only2 animal pus samples were polymicrobial, which is explained as in case of co-infections, culture may be biased towards the more readily cultured organism, yielding an incomplete clinical picture (Hasman et al., 2014). The polymicrobial nature of pyogenic infections may be 
underestimated by routine culture, due to the fastidious nature of many organisms and the loss of viability during transport or from prior antibiotics (Sibley et al. 2012).As such, DNA from skin microbiota may have been introduced during the venipuncture of the skin. This could account for the abundance of Staphylococcus spp. (Rosenthal et al. 2011).B. licheniformis is reported to cause neonatal sepsis (Idelevich et al. 2013).It was found in one sample in a mixed culture, forming pleomorphic colonies with its satellite growth around colonies, with no hemolysis. Thesame result was reported by Idelevich et al.(2013).In recent years, MALDI-TOF MS has emerged as a novel method to identify pathogens causing sepsis via extracting acidsoluble microbial proteins in a size range of 2-20 kDa, which are then analyzed by MS to generate a "mass fingerprint." (Chun et al. 2015).It is suitable for species identification since the generated mass profile comes from ribosomal proteins, which aligns with taxonomic classification (Shitikov et al. 2012). It can be used for early bacterial identification in BCs. It surpassed the conventional methods in speed and accuracy (Foster, 2013). With respect to analyte ionization, MALDI is more sensitive than other ionization techniques, as the laser beam is focused on a small portion of the matrix, allowing efficient energy transfer and preventing destruction of the clinical sample. Moreover, the analytes are widely separated within the matrix, preventing ions clustering that can hamper analysis (Clark et al. 2013).Currently, MALDI-TOF applied directly to positive samples enables microbial identification in less than 1 hour, with a maximum identification rate of $97.3 \%$ of GN bacteria and $98.4 \%$ of GP bacteria (MarchRosselló et al. 2013).Numerous studies reported that it is a rapid, reliable and costeffective method for bacterial identification. However, it has some lacunae: (i) proper identification is only when spectral database has information about specific genes, (ii) databases should be prepared locally for certain taxa as Streptococcus or Staphylococcus in which geographical variations lead to genotypic and phenotypicvariations (Benagli et al., 2011). The main weakness was its inability to identify all organisms in polymicrobial infections or in mixed cultures, as none or, at best, one single isolate could be identified(Leli et al. 2013).

\section{CONCLUSION}

Molecular assays particularly, MALDI-TOF MS significantly reduce the TAT, permitting rapid pathogen ID. Speeding up the TAT of positive $\mathrm{BC}(\mathrm{s})$ is crucial for accurate targeted antibiotic therapy that decreases the mortality rates and antibiotic resistant strains as well with the option to select more potent and less toxic antibiotics, leading to favorable clinical outcome.

\section{REFERENCES}

Afshari A, Schrenzel J, Ieven M, Harbarth S. Bench-to-bedside review: Rapid molecular diagnostics for bloodstream infection--a new frontier? Crit. Care. 2012; 16:222.

Barnini S, Ghelardi E, Brucculeri V, Morici P, Lupetti A. Rapid and reliable identification of Gram-negative bacteria and Gram-positive cocci by deposition of bacteria harvested from blood cultures onto the MALDI-TOF plate. BMC Microbiol. BMC Microbiology; 2015;15:124.

Benagli, C. et al., 2011. Matrix-assisted laser desorption ionization-time of flight mass spectrometry for the identification of clinically relevant bacteria. PloS one, 6(1), p.e16424.

Boutin S, Graeber SY, Weitnauer M, Panitz J, Stahl M, Clausznitzer D. Comparison of Microbiomes from Different Niches of Upper and Lower Airways in Children and Adolescents with Cystic Fibrosis. PLoS One. 2015;10:e0116029.

Cambau E, Bauer M. Multi-pathogen real- 
time PCR system adds benefit for my patients: yes. Intensive Care Med.. 2015;528-30.

Chang W-H, Wang C-H, Lin C-L, Wu J-J, Lee MS, Lee G-B. Rapid detection and typing of live bacteria from human joint fluid samples by utilizing an integrated microfluidic system. Biosens. Bioelectron. Elsevier; 2015;66:148-54.

Chun K, Syndergaard C, Damas C, Trubey R, Mukindaraj a., Qian S. Sepsis Pathogen Identification. J. Lab. Autom. 2015; 3.

Clark AE, Kaleta EJ, Arora A, Wolk DM. Matrix-Assisted laser desorption ionization-time of flight mass spectrometry: A fundamental shift in the routine practice of clinical microbiology. Clin. Microbiol. Rev. 2013;26:547-603.

Deleon C, Shattuck KE, Jain SK. Biomarkers of Neonatal Sepsis. Neoreviews. 2015;16.

Dellinger RP, Levy MM, Rhodes A, Annane D, Gerlach H, Opal SM. Surviving sepsis campaign: international guidelines for management of severe sepsis and septic shock: 2012. Crit. Care Med. 2013;41:580-637.

Dreyer A. Blood Culture Systems: From Patient to Result. Sepsis - An Ongoing Signif. Chall. 2012.

Dubourg G, Raoult D. Emerging methodologies for pathogen identification in positive blood culture testing. Expert Rev. Mol. Diagn. 2015;7159:1-15.

Emonet S, Shah HN, Cherkaoui A, Schrenzel J. Application and use of various mass spectrometry methods in clinical microbiology. Clin. Microbiol. Infect. 2010;16:1604-13.

Faria MMP, Conly JM, Surette MG. The development and application of a molecular community profiling strategy to identify polymicrobial bacterial DNA in the whole blood of septic patients. BMC Microbiol.. BMC Microbiology; 2015;1-16.

Farrell JJ, Sampath R, Ecker DJ, Bonomo RA. “" Salvage Microbiology "”: Detection of Bacteria Directly from Clinical Specimens following Initiation of Antimicrobial Treatment. 2013;8.

Foster, A.G.W., 2013. Rapid Identification of microbes in positive blood cultures by use of the vitek MS matrix-assisted laser desorption ionization-time of flight mass spectrometry system. Journal of clinical microbiology, 51(11), pp.3717-9.

Gaieski DF, Edwards JM, Kallan MJ, Carr BG. Benchmarking the incidence and mortality of severe sepsis in the United States. Crit. Care Med. 2013;41:116774.

Goto M, Al-Hasan MN. Overall burden of bloodstream infection and nosocomial bloodstream infection in North America and Europe. Clin. Microbiol. Infect. 2013;19:501-9.

Hasman, Saputra H, Sicheritz-Ponten D, Lund O, Svendsen C, Frimodt-Møller N, Aarestrup and Frank M 2014. Rapid whole-genome sequencing for detection and characterization of microorganisms directly from clinical samples. Journal of clinical microbiology, 52(1), pp.139-46.

Idelevich, E.A. et al., 2013. Pacemaker lead infection and related bacteraemia caused by normal and small colony variant phenotypes of Bacillus licheniformis. Journal of Medical Microbiology, 62(PART6), pp.940-944.

Iskander KN, Osuchowski MF, StearnsKurosawa DJ, Kurosawa S, Stepien D, Valentine C. Sepsis: multiple abnormalities, heterogeneous responses, and evolving understanding. Physiol. Rev. 2013;93:1247-88.

Jernberg C, Löfmark S, Edlund C, Jansson JK. Long-term impacts of antibiotic exposure on the human intestinal microbiota. 2010;156:3216-23.

Jiang, Q. et al., 2013. Quantification of viable but nonculturable bacterial pathogens in anaerobic digested sludge. Applied microbiology and biotechnology, 97(13), pp.6043-50.

Jordana-Lluch E, Carolan HE, Giménez M, Sampath R, Ecker DJ, Quesada MD. Rapid diagnosis of bloodstream infections with PCR followed by mass spectrometry. PLoS One. Public Library of Science; 2013;8: 62108.

Kaukonen K-M, Bailey M, Pilcher D, Cooper DJ, Bellomo R. Systemic Inflammatory Response Syndrome Criteria in Defining Severe Sepsis. 2015;1-10. 
Kothari A, Morgan M, Haake D a. Emerging technologies for rapid identification of bloodstream pathogens. Clin. Infect. Dis. 2014;59:272-8.

Laakso S. Novel Dna Microarray in Sepsis Diagnostics. 2013.

Leli C, Cenci E, Cardaccia A, Moretti A, D'Alò F, Pagliochini R. Rapid identification of bacterial and fungal pathogens from positive blood cultures by MALDI-TOF MS. Int. J. Med. Microbiol. 2013;303:205-9.

Liesenfeld O, Lehman L, Hunfeld K-P, Kost G. Molecular diagnosis of sepsis: New aspects and recent developments. Eur. J. Microbiol. Immunol. (Bp). 2014;4:1-25.

Loonen AJM, de Jager CPC, Tosserams J, Kusters R, Hilbink M, Wever PC. Biomarkers and molecular analysis to improve bloodstream infection diagnostics in an emergency care unit. PLoS One. Public Library of Science; 2014;9:e87315 (a).

Loonen a JM, Wolffs PFG, Bruggeman C a, van den Brule a JC. Developments for improved diagnosis of bacterial bloodstream infections. Eur. J. Clin. Microbiol. Infect. Dis. 2014;33:1687702 (b).

Lu Y-H, Liu L, Qiu X-H, Yu Q, Yang Y, Qiu H-B. Effect of early goal directed therapy on tissue perfusion in patients with septic shock. World J. Emerg. Med. 2013;4:117-22.

Lukacs, S.L. \& Schrag, S.J., 2012. Clinical sepsis in neonates and young infants, United States, 1988-2006. The Journal of pediatrics, 160(6), p.960-5.e1.

Luo Y, Siu GKH, Yeung ASF, Chen JHK, Ho PL, Leung KW. Performance of the VITEK MS matrix-assisted laser desorption ionization-time of flight mass spectrometry system for rapid bacterial identification in two diagnostic centres in China. J. Med. Microbiol. 2015;64:1824.

March-Rosselló GA, Muñoz-Moreno MF, García-Loygorri-Jordán de Urriés MC, Bratos-Pérez MA. A differential centrifugation protocol and validation criterion for enhancing mass spectrometry (MALDI-TOF) results in microbial identification using blood culture growth bottles. Eur. J. Clin. Microbiol. Infect. Dis. 2013;32:699-704.

Montalvo NF, Davis J, Vicente J, Pittiglio R, Ravel J, Hill RT.Integration of culturebased and molecular analysis of a complex sponge-associated bacterial community. PLoS One. Public Library of Science; 2014;9: 90517.

Mulvey MC, Sacksteder KA, Einck L, Nacy CA. Generation of a novel nucleic acidbased reporter system to detect phenotypic susceptibility to antibiotics in Mycobacterium tuberculosis. MBio. 2012;3: 12-11.

Ngo JT, Parkins MD, Gregson DB, Pitout JDD, Ross T, Church DL. Populationbased assessment of the incidence, risk factors, and outcomes of anaerobic bloodstream infections. Infection. 2013;41:41-8.

Perez KK, Olsen RJ, Musick WL, Cernoch PL, Davis JR, Land GA. Integrating rapid pathogen identification and antimicrobial stewardship significantly decreases hospital costs. Arch. Pathol. Lab. Med. 2013;137:1247-54.

Quiles MG, Menezes LC, Bauab K de C, Gumpl EK, Rocchetti TT, Palomo FS. Diagnosis of bacteremia in pediatric oncologic patients by in-house real-time PCR. BMC Infect. Dis. 2015;15:283.

Rampini, S.K. et al., 2011. Broad-Range 16S rRNA Gene Polymerase Chain Reaction for Diagnosis of Culture-Negative Bacterial Infections. Clinical Infectious Diseases, 53(12), pp.1245-1251.

Ranieri VM, Thompson BT, Barie PS, Dhainaut J-F, Douglas IS, Finfer S. Drotrecogin alfa (activated) in adults with septic shock. N. Engl. J. Med. Massachusetts Medical Society; 2012;366:2055-64.

Reinhart K, Bauer M, Riedemann NC, Hartog CS. New approaches to sepsis: Molecular diagnostics and biomarkers. Clin. Microbiol. Rev. 2012;25:609-34.

Roland, S.P.H. \& Frank, B.M., 2014. SEPSIS BIOMARKERS AND PATHOGEN DETECTION METHODS - STATE OF THE ART. , 9(1), pp.49-61.

Rosenthal M, Goldberg D, Aiello A, Larson E, Foxman B. Skin microbiota: microbial community structure and its potential 
association with health and disease. Infect. Genet. Evol. 2011;11:839-48.

Shitikov E, Ilina E, Chernousova L, Borovskaya A, Rukin I, Afanas'ev M. Mass spectrometry based methods for the discrimination and typing of mycobacteria. Infect. Genet. Evol. 2012;12:838-45.

Sibley CD, Church DL, Surette MG, Dowd SE, Parkins MD. Pyrosequencing reveals the complex polymicrobial nature of invasive pyogenic infections: microbial constituents of empyema, liver abscess, and intracerebral abscess. Eur. J. Clin. Microbiol. Infect. Dis. 2012;31:2679-91.

Singhal N, Kumar M, Kumar Kanaujia P, Singh Virdi J. MALDI-TOF mass spectrometry: An emerging technology for microbial identification and diagnosis Antimicrobials, Resistance and Chemotherapy. 2015;6:1-16.

Siqueira JF, Rocas IN. Microbiology and Treatment of Acute Apical Abscesses. Clin. Microbiol. Rev. 2013;26:255-73.

Stoneking, L.R. et al., 2013. Would earlier microbe identification alter antibiotic therapy in bacteremic emergency department patients? The Journal of emergency medicine, 44(1), pp.1-8.

Takahashi S, Miura N, Harada T, Wang Z, Wang $\mathrm{X}$, Tsubokura $\mathrm{H}$. Prognostic impact of clinical course-specific mRNA expression profiles in the serum of perioperative patients with esophageal cancer in the ICU: a case control study. J. Transl. Med. BioMed Central; 2010;8:103.

Verma, P., 2012. A study on isolation of different type of bacteria from pus. International Journal of Pharmacy and Life Sciences, 3(11), pp.2107-2110.

Verroken a, Defourny L, Lechgar L, Magnette a, Delmée M, Glupczynski Y. Reducing time to identification of positive blood cultures with MALDITOF MS analysis after a 5-h subculture. Eur. J. Clin. Microbiol. Infect. Dis. 2015;34:405-13.

Wang, H.-Y. et al., 2014. Real-time PCR TaqMan assay for rapid screening of bloodstream infection. Annals of clinical microbiology and antimicrobials, 13(1), p.3. 